\title{
Faculty perceptions of grade 7-12 math and science teaching as a career: Evidence from a reduced-basis factor analysis of the Perceptions of Teaching as a Profession in Higher Education Instrument
}

\author{
Jared B. Breakall ${ }^{1}$ \\ ${ }^{1}$ Department of Physics, Colorado School of Mines, 1500 Illinois Street, Golden, CO 80401 \\ Savannah L. Logan ${ }^{1}$, and Wendy K. Adams ${ }^{1}$ \\ ${ }^{1}$ Department of Physics, Colorado School of Mines, 1500 Illinois Street, Golden, CO 80401
}

\begin{abstract}
Teachers in the United States rate their lives better than all other occupation groups, trailing only physicians. However, as a nation we face a shortage of qualified math and science teachers. Because students often turn to faculty members for career advice, it is important that faculty hold accurate and positive perceptions of grade 7-12 math and science teaching. To help identify faculty perceptions of the teaching career, an instrument known as the Perceptions of Teaching as a Profession in Higher Education (PTaP.HE) (Pronounced P-Taffy) was developed. In this work a reduced-basis factor analysis was performed on the PTaP.HE and eight underlying factors were identified. These factors provide insight into faculty thinking about grade 7-12 teaching. When survey data are analyzed by these underlying factors, it is found that faculty perceive themselves and their departments as supportive of those who want to pursue grade 7-12 math or science teaching. However, their perceptions of grade 7-12 math and science teaching are sometimes internally inconsistent, with some perceptions being positive and others negative. This work highlights the importance of sharing accurate information about the teaching career with faculty members, so they can in turn share accurate information with their students.
\end{abstract}

\footnotetext{
2021 PERC Proceedings edited by Bennett, Frank, and Vieyra; Peer-reviewed, doi.org/10.1119/perc.2021.pr.Breakall Published by the American Association of Physics Teachers under a Creative Commons Attribution 4.0 license. Further distribution must maintain the cover page and attribution to the article's authors.
} 


\section{INTRODUCTION}

Teachers in the United States rate their lives better than all other occupation groups, trailing only physicians [1]. Additionally, nearly half of all STEM majors in the US express some level of interest in the teaching profession [2]. Despite these positive findings, recruiting highly qualified STEM teachers continues to be a challenge, as evidenced by the large STEM teacher shortages that exist across the country [3-5].

Our current research is showing that this contradiction between strong teacher well-being, high student interest in teaching, and the STEM teacher shortage, is due in part to inaccurate perceptions of the teaching career. These perceptions tend to fall into categories of teacher work environment, financial stability, and work-life balance [2]. When trusted others, in this case college faculty, hold inaccurate perceptions about grade 7-12 math and science teaching, this can influence how they advise students on teaching as a possible career path [6]. Thus, to recruit more highly qualified STEM teachers in the US, it is critical to address and correct faculty perceptions, so that faculty members can be informed advocates of the teaching profession when advising students about career options.

Previous work [7], reported on the first phases of the development and validation of the Perceptions of Teaching as a Profession in Higher Education (PTaP.HE) (pronounced P-Taffy) instrument, which measures a faculty's perceptions of grade 7-12 teaching as a career. This work included an indepth analysis of interviews with faculty. In those interviews, it was found that many faculty hold inaccurate perceptions about the teaching profession around happiness, retirement, autonomy, salary, retention, and student interest in the career [7].

To further this previous work, here we have conducted a reduced basis factor analysis [8] of the PTaP.HE and identified statistically robust categories of items within the survey. The survey data, when analyzed by these categories reveals further insights into faculty perceptions of grade 712 teaching. These insights can help guide teacher recruitment efforts at colleges and universities nationwide.

This work addresses the following research questions:
1. What empirical underlying factors emerge from a reduced-basis factor analysis of the PTaP.HE?

2. What do these factors reveal about faculty perceptions of grade 7-12 teaching as a career?

\section{METHODS}

\section{A. Perceptions of Teaching as a Profession in Higher Education Instrument}

The PTaP.HE is a survey instrument that consists of 38 Likert scale items and 5 selected response items. The Likert scale items have answer choices from strongly disagree to strongly agree while the selected response items have one correct answer. On average, the survey takes approximately 11 minutes to complete. An example item from the instrument is shown below:

\section{I think grade 7-12 math or science teaching would} be a fulfilling career for a STEM major.

\section{B. Development and Validation}

Perception surveys and concept inventories (such as the PTaP [9] and CLASS [8]) follow a general but consistent four-phase development and validation structure as summarized by Adams and Wieman [10] and to which the PTaP.HE development generally adheres. Here we will focus on the validation efforts in Phase Four as Phases One through Three were described in previous work [7].

Phase Four, the final step of the development is to administer the test to a range of subjects, in this case faculty at a range of institutions, and then perform statistical analyses of the responses to establish reliability and collect further evidence for validity [10]. Here we will focus on the most time intensive aspect of this phase, Factor analysis. Factor analysis uses faculty responses to determine groups of statements that are answered in a correlated manner by faculty, thus revealing aspects of faculty thinking that are closely linked. A factor analysis is particularly useful to perform with perceptions surveys because perceptions can be broad, and novices may organize these ideas quite differently from experts. The emergent categories also provide a simplified way to interpret/score survey results. In this work

TABLE I. Demographic information of participants

\begin{tabular}{cc|cc|cc}
\hline \hline Department & $\begin{array}{c}\text { Participants } \\
(\mathbf{n = 6 0 0})\end{array}$ & Gender & $\begin{array}{c}\text { Participants } \\
(\mathbf{n = 6 0 0})\end{array}$ & $\begin{array}{c}\text { Position Type } \\
\text { Participants } \\
(\mathbf{n}=\mathbf{6 0 0})\end{array}$ \\
\hline Math & 268 & Female & 199 & Tenured & 374 \\
Chemistry & 166 & Male & 370 & Tenure Track & 99 \\
Physics & 158 & Other & 3 & FT Nontenure Track & 63 \\
Other & 4 & Unreported & 28 & PT Nontenure Track & 38 \\
Unreported & 4 & & & Other & 21 \\
& & & & Unreported & 5 \\
\hline \hline
\end{tabular}

The 'Unreported' category in the Gender column includes participants who chose "Prefer not to say" for that item 
we will outline this process and what it reveals about faculty perceptions of grade 7-12 teaching.

\section{Audience/Sample}

To conduct a reduced basis factor analysis, data were collected from 600 faculty members during 2020 from January to December. These faculty members come from 43 different colleges and universities across the United States. Their respective institutions varied greatly in size, location, selectivity, type (private vs. public), and student demographics The faculty respondents vary by gender, department, and position type (Table I). As a note, previous work found that perceptions of the teaching career do not vary significantly by these particular demographics - gender, discipline, or position type. [11].

\section{Reduced-Basis Factor Analysis}

Reduced-basis factor analysis (RBFA) is a dimension reduction technique that is used to identify underlying factors within a survey [8]. Identifying such factors can provide insight into any underlying constructs that may be guiding thinking among survey/test takers. We want to emphasize that these are empirical factors which emerge from the data, statements within these factors are not identified by the researchers.

In RBFA, a principal components analysis (PCA) was conducted using SPSS software utilizing direct Oblimin rotation and extracting factors with eigen values greater than one. Once the PCA identified initial factors, the basis set was reduced and a PCA was performed on each factor individually. This allowed us to see if the factor was truly representing one construct or if there were sub-factors present. If sub-factors existed, item correlations, scree plots, and factor loadings were used to decide which items to add or subtract from the factor, so it truly represents one underlying construct. To ensure each identified factor is robust, statistically valid, and optimized, a robustness rating is produced based on the following formula. This formula has been used to measure robustness in other perceptions instruments [8]:

$$
\text { Robustness }=\left(2 c c+f l+\frac{5|\Delta E|}{N}\right) 3 R^{2}
$$

In this formula, $c c$ is the average absolute value of the correlation coefficients between statements, $\mathrm{fl}$ is the average absolute value of the factor loadings for the category, $\Delta \mathrm{E}$ represents the shape of the scree plot, $\mathrm{N}$ is the number of statements in the category, and $\mathrm{R}^{2}$ is the Pearson product moment correlation. A rating above 6 is viewed as robust.

This iterative process of adding and subtracting items from each factor was repeated until the robustness rating was optimized for each identified factor. Lastly, after factors were identified, a group of 13 experts (STEM faculty who are familiar with grade 7-12 teaching and work closely with teacher preparation) worked together to give each factor a name that best represents the items contained within it. The experts came from large and small universities around the country and consisted of 9 physics, 2 math, and 2 chemistry faculty members.

\section{E. Scoring of the PTaP.HE}

The PTaP.HE instrument is scored according to a percent favorable (expert-like) and percent unfavorable scoring system as seen in other perceptions instruments such as the Colorado Learning Attitudes about Science Survey (CLASS) and CLASS-Chem [8,12].

Consistent with CLASS and the PTaP, for any given item in the instrument, the response scale is collapsed from a 5point scale to a 3-point scale. Agree and strongly agree are combined into one category of "agree" while disagree and strongly disagree are combined into one category of "disagree". Those who choose neutral remain in said category. These responses are collapsed because interviews find that each interviewee had different reasons for differentiating between responses (eg. agree and strongly agree). Further, analyses of largescale data has not found different outcomes when all five responses are retained. After collapsing to a 3-point scale, responses are then compared to the favorable (expert-like) response and are scored as being in agreement with the expert, neutral, or in disagreement.

To analyze survey data by the identified factors, average percent favorable, and unfavorable scores are produced for each factor. To do this for a given factor, each faculty participant receives a score for the percent of statements in that factor where their response is consistent with the favorable response. The favorable response, in many cases, is fact-based, and is simply the correct answer. For the remaining items, the perceptions of those that are successfully involved with the recruiting and preparation of teacher candidates served as the expert response.

The percent agreement scores for each faculty participant in the factor are then averaged (as a mean) for the particular data set. This value is then reported as the percent favorable score for the factor (e.g. Benefits of Teaching). The same process is followed to calculate the percent disagreement with the expert. If a participant chooses neutral on a statement, their response to that statement is not included in either the percent agreement or the percent disagreement scores. The All Students Can Learn factor is scored a bit differently to be consistent with Dweck's work on Growth Mindset [14]. The percent favorable score for this category represents the percent of participants who are in agreement with the expert on all items in the factor. 
TABLE II. Factors within the PTaP.HE

\begin{tabular}{lcc}
\hline \multicolumn{1}{c}{ Factor Name } & $\begin{array}{c}\text { Number } \\
\text { of Items }\end{array}$ & $\begin{array}{c}\text { Robustness } \\
\text { Rating }\end{array}$ \\
\hline All Students can Learn & 3 & 13.3 \\
Supportive Department & 4 & 9.4 \\
Messaging & & \\
Career Options & 3 & 8.8 \\
Benefits of Teaching & 5 & 7.7 \\
Teaching is an Attractive STEM & 5 & 7.5 \\
Career & & \\
Teaching is a STEM Profession & 4 & 6.9 \\
Teacher Work Environment & 5 & 6.1 \\
Facts about Teaching & 4 & 6.1 \\
\hline \hline
\end{tabular}

\section{RESULTS}

Through RBFA, eight underlying factors were identified within the PTaP.HE instrument. Table 2 shows each factor name, number of items, and associated robustness rating. For conciseness, the individual items within each factor are not listed in table 2 but can be found online [13].

When comparing these factors to the interview insights discussed in Pearson, et al., it can be seen that many of the key themes from the interviews are represented by these empirical factors. For example, a common theme that appeared in the interviews and empirical factors concerned the benefits of teaching or the work environment for teachers. Additionally, ideas about teacher's scientific identity are contained in the teaching is a STEM Profession factor. Teacher retention is addressed in Facts about Teaching. Supportive Department Messaging addresses faculty's perspectives of departmental support for those interested in the teaching profession.

Once the factors were identified by the RBFA, and named by the experts, we looked to see if there were any clear patterns emerging. To our group, it seems that there are two "themes". Three of the factors relate to faculty perceptions of teachers and their careers, while four other factors relate to Faculty's perceptions of advising and student career options. For example, the items within 'Teaching is STEM Profession' relate to faculty's views of their students' identity as scientists if they become teachers. The eighth factor, All Students Can learn, is of a separate nature.

After conducting the RBFA, 15 survey items in the PTaP.HE were not placed into factors. This is not fully unexpected since the instrument was developed to be as short as possible. This means some of the constructs/perceptions that faculty hold, may only be touched on with one or two statements, which does not make a factor. Although these items do not fall into a factor, they are retained in the instrument because they represent important perspectives of grade 7-12 teaching, can provide valuable insights when analyzed, and were reliably interpreted items in preliminary think-aloud interviews.

Figure 1 shows a bar chart which represents the average percent favorable scores for each factor that was identified by the RBFA. Table 3 shows average percent favorable scores and the associated standard error on the mean for each factor.

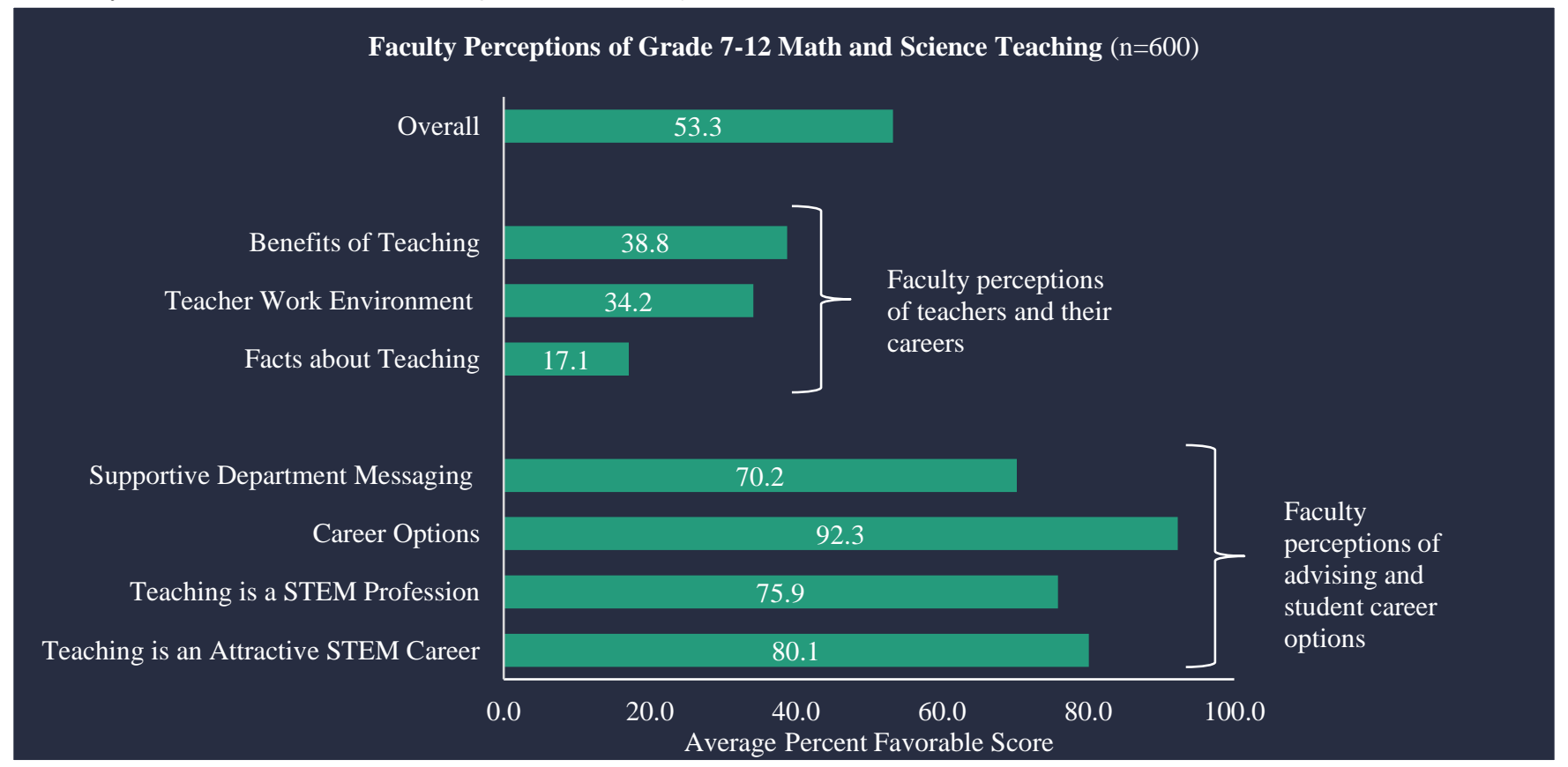

Figure 1. Bar chart showing the average percent favorable scores by factor. The first three factors relate to perceptions of teachers and their careers. The last four factors relate to perceptions of advising and student career options. The Standard Error on the Mean was less than 1.5 for all factors. 


\section{DISCUSSION}

Analyzing PTaP.HE survey responses based on the factors that emerged from the RBFA provide further insight into faculty thinking about the teaching career. In previous work, interviews identified that faculty believe they are supportive of students who want to become teachers [7]. This was validated by these data that show Supportive Department Messaging, Career Options, Teaching is a STEM Profession, and Teaching is an Attractive STEM Career, all have high (over 70\%) average percent favorable scores. For example, as shown in Figure 1, faculty on average answered $70.2 \%$ of the items associated with Supportive Department Messaging favorably. This strengthens our previous qualitative findings that faculty perceive themselves and their departments as supportive of those wanting to pursue grade 7-12 teaching.

However, these data also support previous findings that although faculty perceive themselves as supportive, they tend to some inaccurate perceptions and certain negative views about grade 7-12 teaching. This is shown in Figure 1 where Benefits of Teaching, Teacher Work Environment, and Facts about Teaching all have low (less than 40\%) average percent favorable scores.

Interestingly, a deeper dive into the data finds that faculty are able to hold seemingly inconsistent views with $80 \%$ of faculty agreeing with I think grade 7-12 math or science teaching would be a fulfilling career and $60 \%$ agreeing with the statement $I$ think grade 7-12 math or science teaching would be an enjoyable career day-to-day. Alternately data shows that only $26 \%$ agree with the statement Grade 7-12 teachers in the U.S. rate their lives higher than nearly all other occupation groups and 57\% agree with the statement Grade 7-12 math and science teaching is more stressful on average than other careers.

This suggests that while college STEM faculty perceive themselves and some of the other faculty in their departments as supportive of those wanting to pursue grade 7-12 teaching as a career (average factor percent favorable scores of 70.2, $92.3,75.9$, and $80.1 \%$ ) they do not necessarily have completely accurate or positive perceptions of what a career as a grade 7-12 teacher would be like (average factor percent favorable scores of $38.8,34.2$, and 17.1).

This is problematic because STEM students often look to faculty for career advice [6]. Thus, if faculty hold inaccurate views about the teaching career, they may knowingly (or unknowingly) pass these perceptions onto their students and potentially steer interested students away from grade 7-12 teaching. We have seen through student survey data and student focus groups that students at institutions across the country perceive many faculty in their department are not supportive of this career option [15].

These data highlight the importance of sharing accurate information about the teaching career with faculty. By doing so, efforts to recruit more highly qualified STEM teachers in the United States will be more successful.

Accurate information about grade 7-12 teaching can be found at getthefactsout.org. Additionally, research-based and user-tested resources that can be used to share accurate information about grade 7-12 teaching with students and faculty members are also available on the website. There are specific faculty-facing resources such as posters, videos, and PowerPoint presentations that can be customized and used in your teacher recruitment efforts.

\section{LIMITATIONS}

Due to our recruitment efforts' focus on departments that are actively working to recruit students into math and science teaching, it is likely that these data may be skewed to those who have an investment in STEM teacher preparation and potentially more expert-like perceptions of the profession compared to the average U.S. STEM faculty member.

\section{ACKNOWLEDGMENTS}

We'd like to acknowledge the GFO project team and all the faculty participants who made the time to complete the survey. This work is supported by the NSF under Grant Nos. $1821710 \& \underline{1821462}$. Any opinions, findings, and conclusions or recommendations expressed in this material are those of the author(s) and do not necessarily reflect the views of NSF. 


\section{REFERENCES}

[1] S. Lopez, P. Sidhu, U.S. (2013) Teacher love their lives, but struggle in the workplace. News.gallup.com. Retrieved June 4, 2021

[2] M. Marder, R. . Brown, and M. Plisch, Recruiting Teachers in High-Needs STEM Fields: A Survey of Current Majors and Recent STEM Graduates, A Report for the American Physical Society Panel on Public Affairs (College Park, MD, 2017).

[3] N. Malkus, K. M. Hoyer, and D. Sparks, Teaching vacancies and difficult-to-staff teaching positions in public schools (NCES 2015-065), no. November, pp. 128, (2015).

[4] Educator Supply \& Demand in the United States Report (Slippery Rock, PA, 2014).

[5] Aragon, $S$, (2016). Teacher Shortages: What We Know. Teacher Shortage Series. Education Commission of the States, (May), 1-12. Retrieved May 22, 2020 from https://eric.ed.gov/?id=ED565893.

[6] Major Influence: Where Students Get Valued Advice on What to Study in College. Strada Education Network, (2017).

[7] R. Pearson III, S. Logan, W. Adams. (2020) Faculty perception insights obtained from faculty interviews during the development of the Perceptions of Teaching as a Profession in Higher Education (PTaP.HE) instrument. Physics Education Research Conference Procedings, pp. 394-399

[8] W. Adams, K. Perkins, N. Podolefsky, M. Dobson, N. Finkelstein, C Wieman (2006) A new instrument for measuring student beliefs about physics land laerning physics: The Colorado Learning Attitudes about Science Survey. Physical Review Special Topics- Physics Education Research, 2(1), 1-14

[9] W. Adams, (2017) A new survey uncovers strong mispercpetions about the teaching profession: What can we do to get the facts out? APS Forum on Education.

[10] W Adams, \& C. Wieman, (2011). Development and validation of instruments to measure learning of expertlike thinking. International Journal of Science Education, 33(9), 1289-1312.

[11] J. Breakall, S. Logan, R. Pearson, B. Pyper, W. Adams. (2020) Maybe we aren't that different after all: Faculty perceptions of grade 7-12 teaching as a career. 2020 PERC Proceedings [Virtual Conference, July 22-23, 2020] doi:10.1119/perc.2020.pr.Breakall.

[12] J. Barbera, W. K. Adams, C. E. Wieman, and K. K. Perkins, Modifying and validating the Colorado learning attitudes about science survey for use in chemistry $J$. Chem. Educ. 85, 1435 (2008).

https://drive.google.com/file/d/1vWw26AiWfAuwrPx6T HljEK pPLYUczw7/view? usp=sharing

[14] C. Dweck. (2008) Mindsets and math/science achievement. Advaned Study Commission on Mathmatics and Science Education

[15] S. L. Logan, J. B. Breakall, R. L. Pearson III, and W. K. Adams, College faculty support for grade 7-12 teaching careers: survey results and comparisons to student perceptions, 2020 PERC Proceedings [Virtual Conference, July 22-23, 2020], edited by S. Wolf, M. B.
Bennett, and B. W. Frank, doi:10.1119/perc.2020.pr.Logan. 